\title{
Analysis on the Trend of Sewage Treatment Technology Patent in Dalian, China
}

\author{
Fengying Huang ${ }^{1,2}$, Yubo Cui ${ }^{1,2, *}$, Wanjun Zhang ${ }^{1,2}$, Luosangzhuma ${ }^{1,2}$, Zhongwei Zhang ${ }^{1,2}$ \\ ${ }^{1} \mathrm{~K}$ ey Laboratory of Biotechnology and Bioresources Utilization, M inistry of Education, Dalian M inzu University, Dalian $116600, \mathrm{China}$ \\ ${ }^{2}$ College of Environment and Resources, Dalian Minzu U niversity, Dalian 116600 , China
}

\begin{abstract}
The development status and trend of the patents related to sewage treatment technology in Dalian, China in the past decade may affect the future environmental protection industry development. The status quo of patent applications related to wastewater treatment technology was analyzed from the perspectives of application volume, disclosure volume, application organization, type composition of invention and utility model patent products and legal status. The results indicated that the total number of filed patents were 894 , and the number of issued patents were 914 in recent ten years, showing an increasing trend for sewage treatment technology in Dalian,China. However, there were distinct differences between the application agencies of invention patents and utility model patents. M ost of the invention patents came from universities, with 264 in the top five, and most of the utility model patents came from enterprises, with 134 in the top five. A mong the product types, the highest number of patent applications was water, wastewater, or sludge treatment technology, a total of 761. A this point, the two patent directions had the same trend. In the state of law, although the number of applications and disclosures was 470 , which was more than 416 actually authorized, it was not difficult to find that sewage treatment industry in Dalian, China was in an increasingly developing stage and the patents actually obtained had higher quality assurance. In conclusion, this essay from the perspective of patent application made a simple explanation the future development of sewage treatment industry and the problems existing in the practical application of sewage treatment technology. Finally, from the perspective of patent application, the paper analyzed the future development of sewage treatment industry and the problems existing in the practical application of sewage treatment technology.
\end{abstract}

\section{Development trend of sewage treatment technology patent in Dalian}

\subsection{Comparison of annual filed patents and issued patents}

A total of 894 filed patents of sewage treatment technology were published by The State Intellectual Property Office in Dalian from 2009 to 2019, and the development trend of the annual filed patents and annual issued patents were shown in Fig.1.

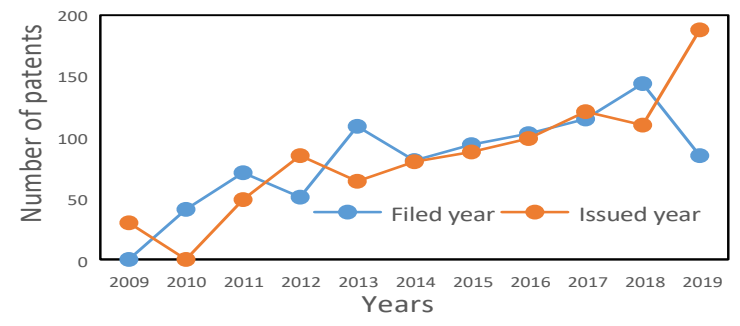

Fig. 1. Trend graph on sewage treatment technology filed patents and issued patents in Dalian.
In the Fig.1, the blue line showing the trend of filed patents in annual, and the red line showing the trend of issued patents in annual.In decade, this denoted number of filed patents for sewage treatment technology in Dalian began to increased with the moderate growth rate from 2009, and the number of filed patents reached the first peak of 109 in 2013 .The number of filed patents increased slightly from 2014 to 2016 , but the number of filed patents and the number of issued patents showed an obvious upward trend over than before 2013. From 2017 to 2019 , it showed a trend of firstly increase and then decline soon, reaching a peak of 144 in 2018. However, the number of issued patents had shown an overall trend of increasing in the past decade, with the highest number reaching 188 in 2019.

The phenomenon shown in Fig.1.does not represented all the actual situation such as the number of 2009 filed patents and the number of 2010 issued patents were both 0 . Because of issued patents time and filed patents time are inconsistent, and the former has hysteresis.In the first half of 2009 , there may still be patent documents that have been filed but have not been

\footnotetext{
* Corresponding author: cyb@dlnu.edu.cn
} 
issued at the time of this retrieval.It also reflected in the number of issued patents in 2019.

From 2009 to 2012, there were 163 filed patents for sewage treatment technology in Dalian, and from 2013 to 2019, there were 731.It can be seen that the overall filed patents have shown an increasing trend since 2013, and a new high in 2013.It has also been a slight increased in recent years.

\subsection{Analysis of application organization}

The statistics of the top 5 institutions in Dalian for patent applications for sewage treatment technology inventions are shown in Fig.2. They are Dalian University of Technology, Dalian Jiaotong University, Dalian Petrochemical Research Institute, Dalian Chuangda Technology Trading Market Company Limited, and Dalian Maritime University respectively. The number of Dalian sewage treatment technology invention patent applications for these five institutions is 264 , accounting for $38.22 \%$ of the total.In particular, Dalian University of Technology, which ranks first, has a total of 174 applications, accounting for $24.27 \%$. It is the main institution for patent applications for sewage treatment technology inventions in Dalian .

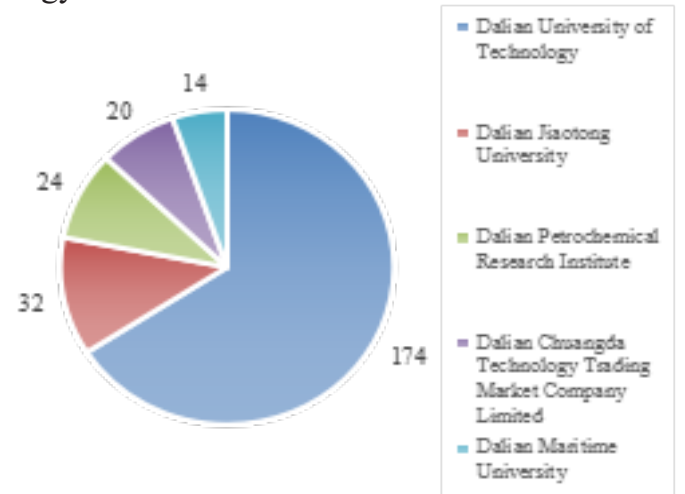

Fig.2. Top five statistics on the number of patent applications for sewage treatment technology inventions in Dalian.

The statistics of the top 5 institutions in Dalian for patent applications for sewage treatment technology utility model patents are shown in Fig.3. They are Dalian Dakai Sewage Treatment Company Limited, Dalian Dagushan Sewage Treatment Company Limited, Dalian Hengji Xinrun Water Company Limited, Dalian Mike Environmental Technology Engineering Company Limited. And Dalian Wangyang Environmental Engineering Company Limited. The number of utility model patent applications from these five institutions is 134 , accounting for $30.52 \%$ of the total number of applications. In particular, Dalian Dakai sewage treatment Company Limited, which ranks first, has a total of 42 applications, accounting for $9.57 \%$. It is the main organization for utility model patent applications of sewage treatment technology in Dalian.

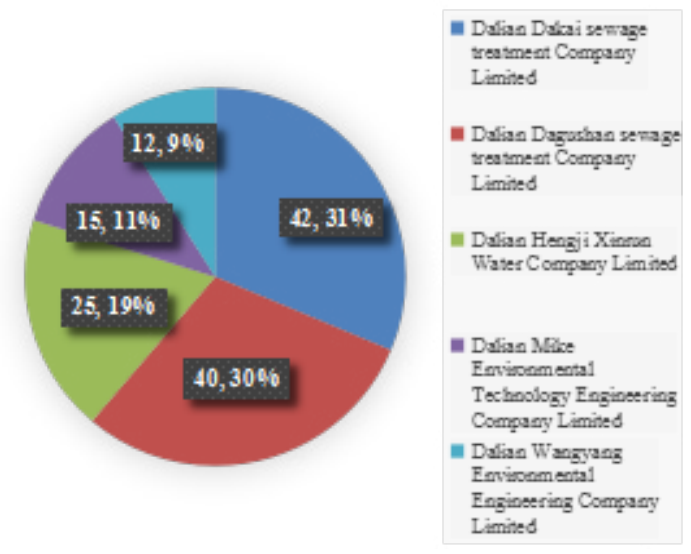

Fig.3. Statistics on the top five patent applications for utility models of sewage treatment technology in Dalian.

From the above data, it is not difficult to find that there are some differences between the application institutions of invention patent and utility model patent. Specifically, colleges and universities are the main institutions for invention patent applications, while sewage treatment environmental protection companies are the main institutions for utility model patent applications. However, the total number of utility model patent applications is 134 far less than that of invention patents.

\subsection{Analysis on the types of invention patent and utility model patent}

The technical types of patented products of sewage treatment technology invention patent in Dalian were shown in Fig.4.As can be seen from Fig.4, the invention patent of sewage treatment technology in Dalian is mainly divided into five main parts: treatment of water, waste water, sewage or sludge,separation technologies, methods or devices for directly converting chemical energy into electric energy, chemical or physical methods, microorganisms or enzymes and their compositions.Among them, 490 patents were applied for water, wastewater, sewage or sludge treatment, accounting for $77.1 \%$ of the total invention patents for sewage treatment technology in Dalian, followed by 49 separation technologies, accounting for $7.8 \%$. There were 42 methods or devices for directly converting chemical energy into electrical energy, accounting for $6.6 \% ; 31$ chemical or physical methods, accounting for $4.9 \%$; and 24 microorganisms or enzymes and their compositions had the lowest number of applications, accounting for $3.8 \%$. It can be seen that among the invention patent applications, there are the most invention patent applications for the treatment of water, wastewater, sewage or sludge, which shows that the current innovation direction of water, wastewater, sewage or sludge treatment is relatively concentrated, while other directions are relatively weak. 


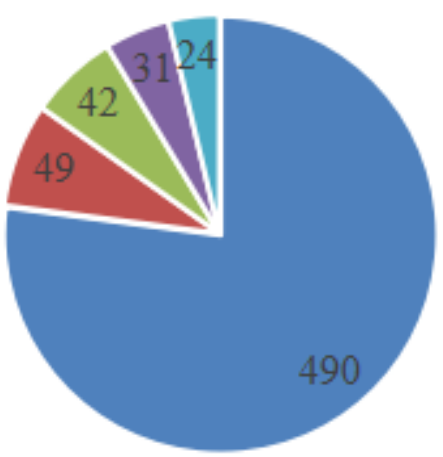

- Treatment of water, waste water, sewage or sludge

- Separation

technologies

- Methods or devices into electric energy

- Chemical or physical methods

- Microorganisms or enzymes for chemical energy

Fig. 4 .Technical types of patented products of invention.

The technical types of utility model patented products for sewage treatment in Dalian are shown in Fig.5.As can be seen from Fig.5, Dalian sewage treatment technology utility model patent is mainly divided into five main parts: water, wastewater, sewage or sludge treatment, separation technologies, test or analysis of materials with the help of the chemical or physical properties of materials, mix and general clean.

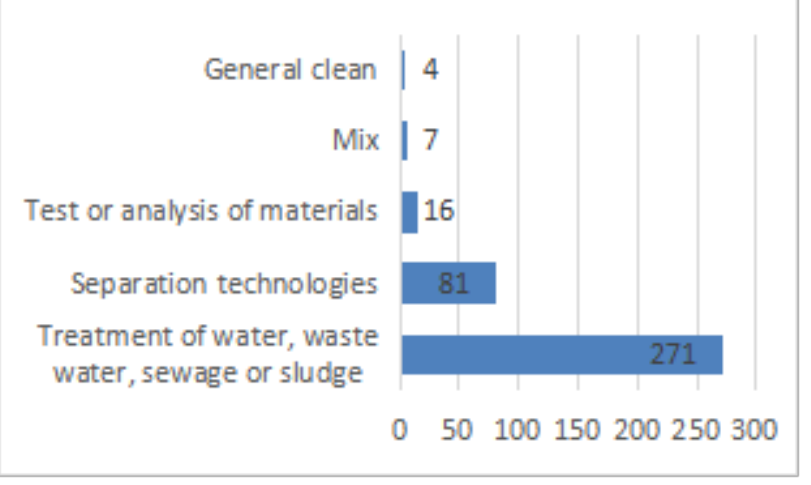

Fig. 5. Technical types of patented products of utility model.

Among them, 271 of water, waste water, sewage or sludge treatment technology were applied the highest, accounting for $71.5 \%$ of the total practical model patents of sewage treatment technology in Dalian, followed by 81 of separation, accounting for $21.4 \%$. 16 of test or analysis of materials with the help of the chemical or physical properties of materials,accounting for $4.2 \% ; 7$ were mix, accounting for $1.8 \%$; and 4 general clean were applied, with the least number of applications, accounting for $1.1 \%$.It can be seen that the utility model patent is similar to the invention patent. At present, the innovation direction of water, wastewater, sewage or sludge treatment technology in Dalian is more concentrated.

It can be seen from the number of applications for invention patents and utility model patents that the focus is on the treatment of water, waste water, sewage or sludge.No matter in theory or in practical application, the treatment of water, wastewater, sewage or sludge has always been the most common and basic,but most difficult problem in sewage treatment.This paper takes the municipal sewage treatment plant as an example.Although the mature $\mathrm{A}^{2} \mathrm{O}$ process can greatly reduce the indicators of pollutants in sewage, due to the particularity of water quality and environment, a variety of thorny problems often appear in the process of operation, thus influencing the effluent quality. in serious cases, it may even paralyze the system.

\subsection{Analysis of patent legal status}

The legal status of patents for sewage treatment in Dalian was shown in Fig.6.From 2009 to 2019, only 470 sewage treatment technology patents in Dalian were effectively authorized, accounting for $44.0 \%$ of the total; 182 applications for sewage treatment technology patents were still under review; 416 invalid patents were caused by various factors, accounting for $38.9 \%$ of the total.

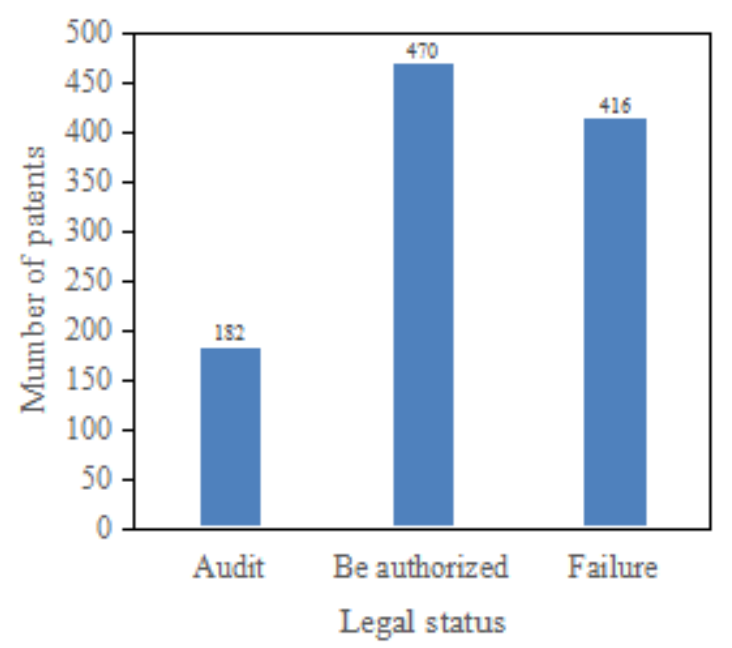

Fig.6. Patent legal status

\section{Industry development analysis from the viewpoint of patent application}

As the analysis results, it can be seen that Dalian sewage treatment technology patent applications have been on the rise since 2010, and the number of applications reached the first historical peak in 2013, but the number of patent applications has declined slightly since 2014.The patent applications for sewage treatment technology in Dalian are mostly focused on inventions, most of which are in the direction of water, wastewater, sewage or sludge treatment.On account of there are too many unstable factors in the process of water, wastewater, sewage or sludge treatment, the problems that need to be solved in this direction have become the focus.In the patents of sewage treatment technology in Dalian, the products are mainly used to solve the problems in practical application, which leads to the long examination time and low pass rate in patent applications.In addition, in recent years, many other fields can also be very efficient, energy-saving and lowcost to solve the problems arising in practical application, resulting in a significant reduction in patent applications, so the total number of patents for sewage treatment technology in Dalian also shows a decline trend.The patent consciousness of some enterprises and universities 
is very high. Dalian Dakai Sewage Treatment Company Limited and Dalian University of Technology are the most prominent representatives, which expand their influence, improve the competitiveness of enterprises and the popularity of colleges and universities.

\section{Problems in the development of urban sewage treatment patent}

The result of patent information analysis shows that the number of patent applications for sewage treatment in Dalian has shown an increase trend in recent years, which not only reflects that the state attaches great importance to the cause of sewage treatment, but also reflects the change of personal views on environmental protection. It is everyone's responsibility to take care of the environment.However, the problems existing in the patent development of urban sewage treatment can not be ignored, and some problems those are not easy to be solved cannot be ignored because of the environmental protection in the general environment.For example, in recent years, with the in-depth study of the demand for the utilization and protection of environmental resources, the problems of foam and scum of biochemical ponds in sewage treatment plants are often encountered by sewage treatment engineers, but also a headache. In the practical engineering application of the sewage treatment plant, the spiral scraper can not touch the bottom of the pool completely, so that the sludge precipitated on the bottom of the pool can not be treated completely, and in serious cases, there will be a very dense layer of sludge stuck to the bottom of the pool. This is a common problem in the process of practical engineering application. If the development of patents shows an upward trend, but fails to solve the real problems in practical application, it will not only bring disadvantages to the development of patents, but also to the cause of sewage treatment.

\section{Acknowledgements}

The research was financed by the Science and Technology Innovation Foundation of Dalian, China (2018J12SN080) and Natural Science Foundation (National Innovation Joint Fund) of Liaoning, China.

\section{References}

1. C.B.YE, Z.M.ZHOU, W. LV, Q. LIU, JJ. ZHANG, China Water \& W astewater, Research Progress on A 2O Process for Sewage Treatment, 30, 135-138, (2014)

2. Y. ZHAO, C.B. YE, K. ZHAO, Q. LIU, J.J. ZHA NG, China W ater \& W astewater, Upgrading of A 2O Process in Treatment of Sewage, 31, 90-93, (2015)

3. X.WANG, Z. WANG, W.T. YANG, X.J. XI, L.Y. SHI, W.Y. DONG, Q. ZHSNG, Y.N. ZHOU, Environmental Engineering, Shortage of Water
Resources in China and Countermeasures, 32, 1-5, (2014)

4. L.J. ZHAO, D.Q. ZHANG, B.Z. CHEN, China Water \& Wastewater, R,Progress of sludge treatment and disposal Technology, 06, 23-25, (2001)

5. F.X. TAN, S.J. HOU, H.L. WANG, L.L. XIE., Environmental Engineering Proceedings of the National academic Annual meeting in 2019, Status Analysis of Sewage Treatment Patents and Development Trend, 79-82+86, (2019)

6. Industral Water \& Wastewater, Water treatment patent, 50, 83, (2019)

7. W.H. YANG, Hebei Agricultural University, Research on the Theory and Technology of purification and reuse of Urban domestic sewage, (2005)

8. Y.Y. CAI, E.Z. LIU, China High Technology Enterprises, Analysis on technological Development and Innovation capability of sewage treatment Industry in China, 17, 7-10, (2012)

9. S.H. PENG, L.X. DONG, Y.L. ZHANG, D.L. WU, Environmental EngineeringResearch, Progress on Patent of Rural domestic sewage treatment Technology, 36, 1-5, (2018)

10. J. YIN, X.J.TAN, G.P. LIA O, J.L. ZHAI, G.D. LIU, China Water \& Wastewater, Characteristics and disposal status of municipal sewage sludge in China, 21-24, (2003) 